\title{
The Application of Wireless Communication in IOT for Saving Electrical Energy
}

\author{
https://doi.org/10.3991/ijim.v14i01.11538 \\ Haider Th. Salim AlRikabi (四) \\ Wasit University, Wasit, Iraq \\ hdhiyab@uowasit.edu.iq \\ Khalid Waleed Nasser \\ Misan University, Amarah, Iraq \\ Abdul Hadi M.Alaidi \\ Wasit University, Wasit, Iraq
}

\begin{abstract}
Energy consumption is a huge problem in Iraq, especially in government institutions. Many devices continue operating even after working hours. In this case study, by using IOT technology, we shall show it to be more efficient if we can control the main devices that are consuming a large amount of power. Internet of things (IOT), therefore, is an exciting solution for managing energy consumption in Iraqi government buildings.

The proposed system has been designed to wake up the devices to start operating at 7:00 AM. 7:00 AM is the standard start of the working day in Iraq. In our proposed system, the case study has been taken based on the universities and institutions. In the universities and institutions, the working day ends at 8:00 PM. This is when our proposed system is designed to power off the main devices. In addition, after 8:00 PM and before 7:00 AM, if there is any device still in operation, the system will send a notification to the manager of the institution.

Our proposed system has been designed using Arduino mega as a main controller. Also, the module SIM800L GSM has been used to make the communication for notification cases, and the Relay $8 \mathrm{CH}$ has been used as electronic switches for the devices.
\end{abstract}

Keywords - Internet of Things (IOT), Power management, Global System for mobile communication (GSM).

\section{Introduction}

The sensor nodes of the devices play a very important role in Internet of things (IOT) applications. The IOT edge devices number is predicted to be millions, trillions, or more, and they must operate with low power consumption like $1 \mathrm{~mW}$ or less [1]. However, each IOT device that is working in $1 \mathrm{~mW}$ for power management will help to reduce the power consumption in the building or the institution. The saving of 
energy consumption in the building is by reducing the loss of energy. Now, this is commonly referred to as "improving the efficiency of the energy in the buildings" by the rational use of energy. Specifically, the energy saving of the buildings is referred to in relation to the building design, planning, construction (expansion and reconstruction), the process of using and transformation and carrying out the standards of the energy efficiency in the implementation[2, $\underline{3}]$. Also, in the usage of the materials, equipment, techniques, products and technologies of energy saving, improving the performance of heating and thermal insulation, refrigeration of the air conditioning and heating system efficiency, strengthening the management and operation of energy systems, and using renewable energy [4].

"Internet of things" is the term that refers to any object that communicates with the Internet. Next, via the network of the mobile communication or any other way to access the connection to the Internet, the collection of information and its intelligent management will be achieved in energy savings, and decrease of the energy consumption in the building or in the institutions[5].

There are three characteristics in the IOT systems. The first one is the collection of information using any wireless technique; the second one is the real-time delivery of the data packets; and the last one is the process and the analysis of the collected data. The IOT systems consist of three levels. The bottom level is associated with sensory data; the second level is related to the network layer for the transmission of the data; and the top level offers the service which is the application layer [3].

In recent years, a large number of researchers and power service companies have been contacting consumers in regard to the saving of energy. Aryo H. Primicanta and etc. in 2010, developed a wireless power monitoring system that is based on the Zigbee and GSM technology, the result of this work leads to monitoring the power consumption of the customers and leads to savings in the consumption of energy[ 6 ].

N. Javaid and etc. in 2012 discussed power organizing, power utilization, and the architecture of power controlling with the intention of power saving. They also discussed the Zigbee role in the real-time reading of the meter, transmission line monitoring, and the direct controlling of the load for the electric appliances used in the homes. They also discussed the control of home appliances, so that it appears as userfriendly for power on/off via the Internet, PDA by using the GUI Web-portal, and via the GSM mobile phone[7].

Vishal S. Undre and etc. in 2014 developed a new method which is an energy management method that is advanced and uses GSM technology. In this design, the electrical energy that is available will be distributed to each consumer in equal quantities. This required energy value is set via the GSM shield. If there is a consumer that exceeds the limit of the consumption value then an offset current card will give a signal to the microcontroller and the microcontroller will activate the relay, which results in a cut off of the power supply to that particular consumer[8].

Waqas Ali and etc. in 2017 presents an efficient, simple, and inexpensive system design of an energy meter for the automatic single phase reading. This system is based on GSM technology which, in addition, has the advantage of user notification. The short messaging service has been used in this system for sending the readings of the energy meter data to the office of billing as well as for updating the consumers about 
their usage of the energy on a regular basis. In addition, this work also discusses the impacts of the system's potential that is used both for consumers and utilities[1].

\section{System Design and Implementation}

In this section, the proposed design and its implementation will be discussed in details. This section contains two sub-sections; the first one talks about the hardware design, and the second talks about the software design.

\subsection{Hardware design part}

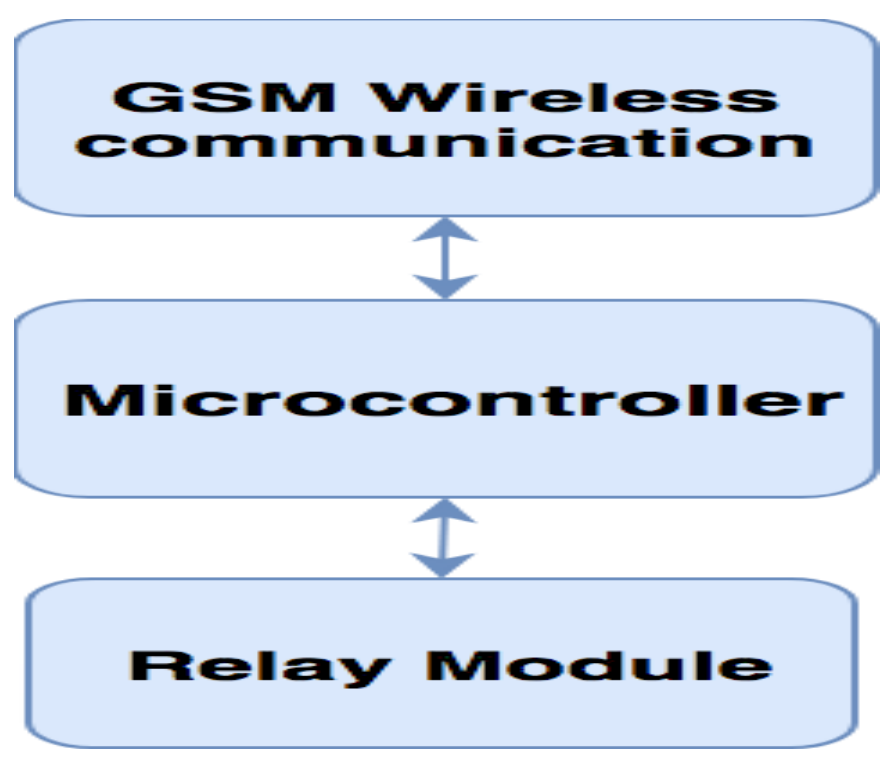

Fig. 1. The general block diagram of the proposed system.

In this section, the hardware design of the proposed system will be discussed in detail. The main part of this system is the microcontroller that acts as the brain of the system. This system uses the GSM technology for wireless communication for transmitting the data. Also, there is an android app that has been designed for this system which is related with the system to enable wireless controlling by the manager of the power service in the institution. Figure (1) shows the main block diagram of the proposed system. The microcontroller that has been used in this system is the Arduino mega microcontroller, and the GSM shield that has been used for the wireless communication is SIM800L; also, an 8-channel relay module has been used as an electronic switch. Figure (2) below shows the connection diagram of the proposed system. 


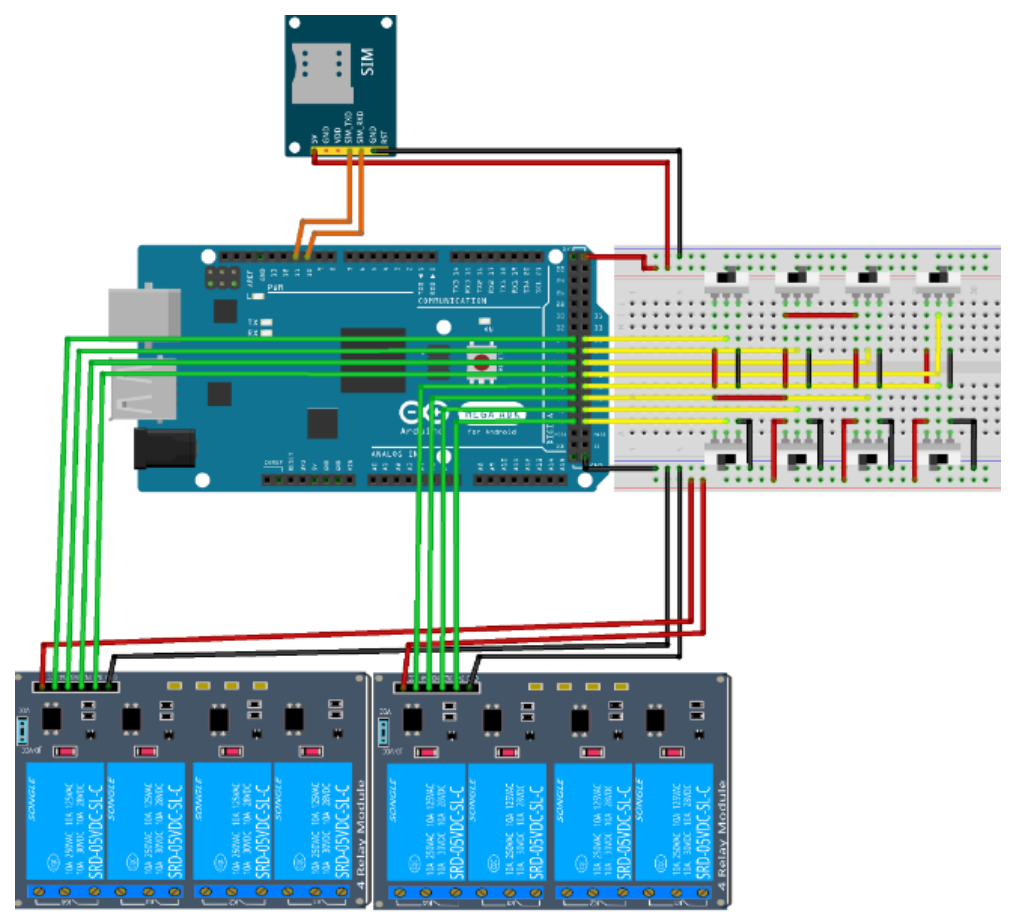

Fig. 2. Shows the connection diagram of the proposed system.

As shown in the figure above, the proposed system also contains 8 on/off switches, which are to give manual control of the electrical devices. Also, in case any device operates outside of the working period by using the switches, the system will give a notification to the manager of the institution by using the SMS service of the GSM communication. The manager of the institution has the android application that is able to control these devices wirelessly by using the buttons that are related with the SMS service of the device.

\subsection{Software design part}

In this section, the software part of the proposed system will be discussed in detail. In the first, the software of the Arduino microcontroller will be discussed, and thereafter, the software of the android application will be discussed.

The Arduino mega has been programed using the $\mathrm{C}++$ programing language by using the AVR studio development environment. The algorithm that is shown in Figure (3) can be explained in the following listed points:

- The system will switch on the essential devices at 7:00 AM.

- The system gives the ability to control the devices by using the on/off switches.

- At 8:00 PM, the system will switch off important devices.

- Any device that is switched off after 8:00 PM and is switched on again. 
- By using the switches, the system will send a notification to the manager.

- The manager has the means to switch on/off the devices by using the android application.

- The android application is related with an SMS service in the mobile phone for sending SMS messages to the system.

- The system gives priority to the SMS messages because they are from the manager of the institution.

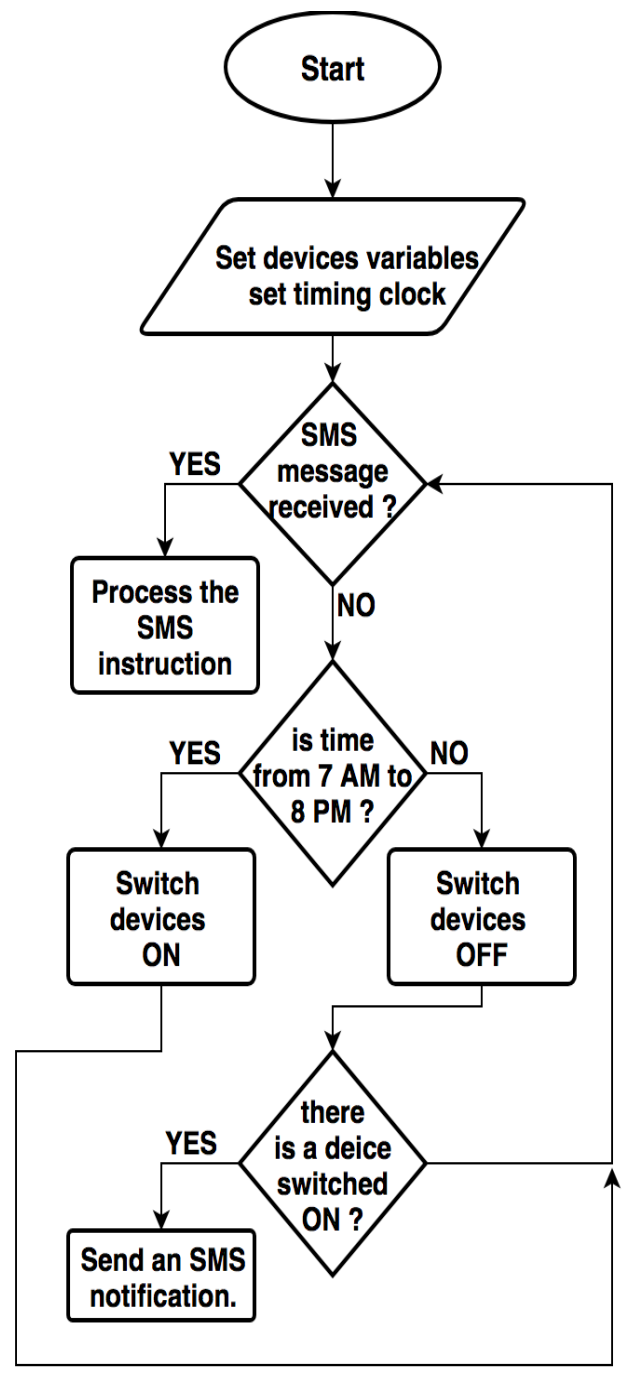

Fig. 3. The flowchart of the algorithm for the proposed system

In Figure (3), the flowchart of the algorithm for the proposed system is explained. 


\subsection{Android APP development part}

For the proposed system, there is an android app that has been developed. This application has been developed using the Android Studio Development Environment. The purpose of the android app is for controlling the devices wirelessly via the GSM communication technology. The application contains a set of buttons that are programed to send specific commands when they are clicked. These commands are accepted by the system, and by these commands, the system will control the devices.

\subsection{The prototype}

The proposed system has been implemented as a prototype system. The system contains eight devices that are managed and controlled, as shown in the next Figure (4), which shows the proposed implementation of the prototype

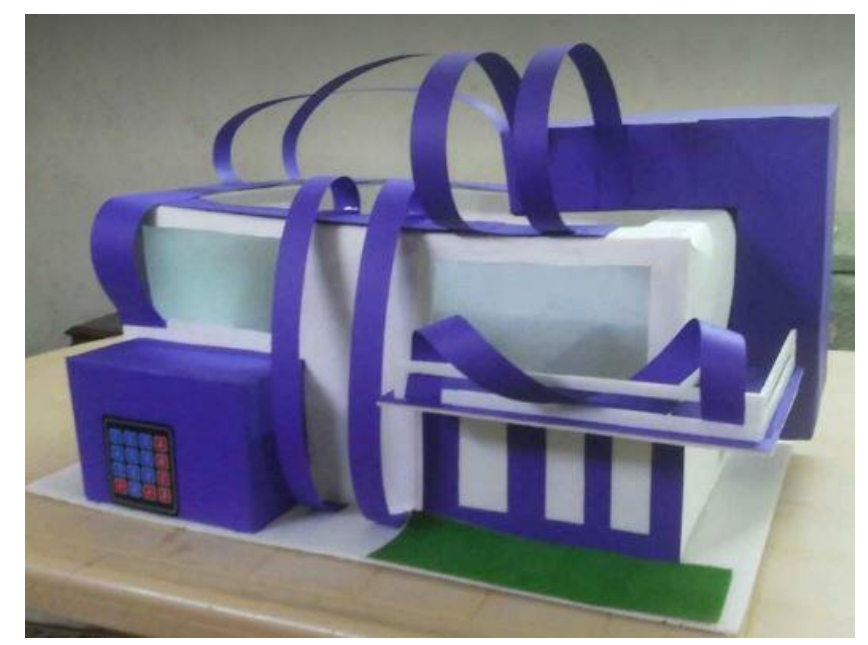

Fig. 4. The prototype of the propose system.

\section{Results and Conclusion}

Our proposed system has been tested in prototype design. It approved that the energy that are consumed in one month has been decreased up to $50 \%$ as shown in figures (5) \& (6) below. 


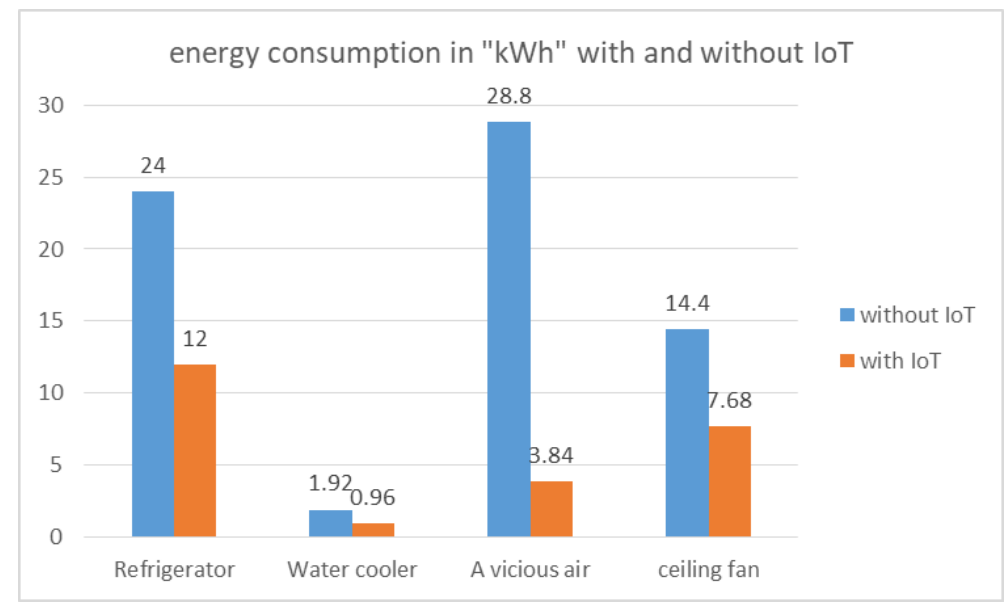

Fig. 5. Energy consumption for refrigeration \& air refreshing

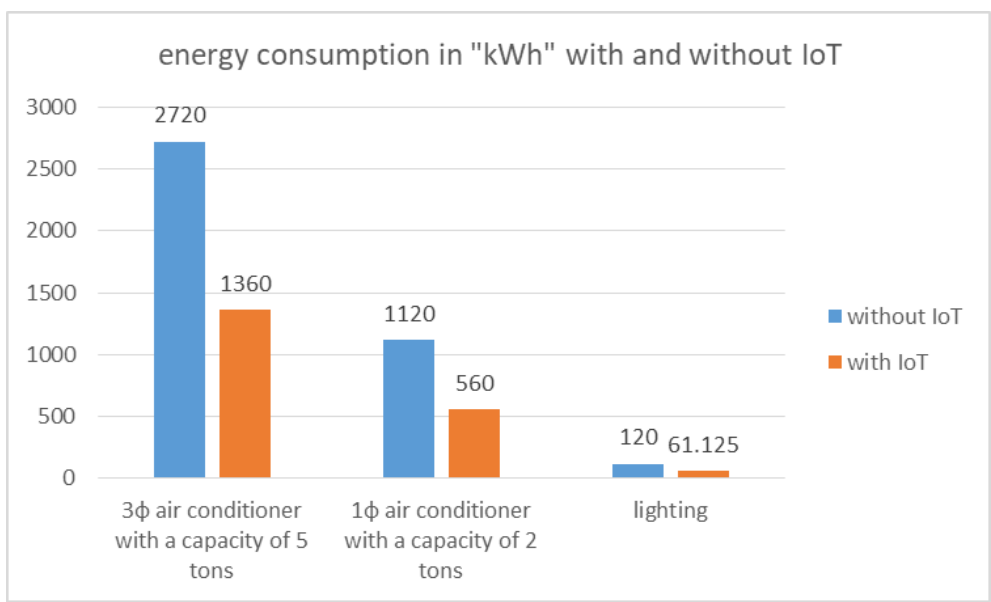

Fig. 6. Energy consumption for cooling \& lighting

This system proves that using of the wireless communication with IOT systems will help to save energy. By comparing the proposed system with recent works, the proposed system allows the manager of the institution to have direct access to the energy-saving system. The proposed system also lets the manager of the institution be notified in case of any accident.

The energy saved/gained by using IOT applications in this work is calculated as:

$$
\begin{gathered}
E_{G}=E-E_{\text {IoT }} \\
E_{G}=4022.4 \mathrm{kWh}-2012.125 \\
E_{G}=2010.275 \mathrm{kWh}
\end{gathered}
$$

Where

EG: daily gained energy after using IOT

E: daily energy consumed without using IOT 
EIOT: daily energy consumed with using IOT

For calculating the gained efficiency $(\eta \mathrm{G})$ the below equation is used

$$
\begin{gathered}
\eta_{G}=\frac{E_{G}}{E} * 100 \% \\
\eta_{G}=\frac{2010.275}{4022.4} * 100 \% \\
\eta_{G}=49.97 \%
\end{gathered}
$$

The equation given above shows that energy efficiency by using IOT for monitoring and notifying saved about $50 \%$ of the daily energy consumed.

\section{References}

[1] W. Ali, H. Farooq, A. Khalid, A. Raza, and N. Tanveer, "Single phase GSM based wireless energy metering with user notification system," in 2017 International Symposium on Wireless Systems and Networks (ISWSN), 2017, pp. 1-8: IEEE. https://doi.org/10.1109/ iswsn.2017.8250030

[2] B. L. R. Stojkoska and K. V. Trivodaliev, "A review of Internet of Things for smart home: Challenges and solutions," Journal of Cleaner Production, vol. 140, pp. 1454-1464, 2017. https://doi.org/10.1016/j.jclepro.2016.10.006

[3] C. Wei and Y. Li, "Design of energy consumption monitoring and energy-saving management system of intelligent building based on the Internet of things," in 2011 international conference on electronics, communications and control (ICECC), 2011, pp. 3650-3652: IEEE. https://doi.org/10.1109/icecc.2011.6066758

[4] P. V. Paul and R. Saraswathi, "The Internet of Things - A comprehensive survey," in 2017 International Conference on Computation of Power, Energy Information and Commuincation (ICCPEIC), 2017, pp. 421-426: IEEE. https://doi.org/10.1109/iccpeic.2017.8290405

[5] I. Khajenasiri, A. Estebsari, M. Verhelst, and G. Gielen, "A review on Internet of Things solutions for intelligent energy control in buildings for smart city applications," Energy Procedia, vol. 111, pp. 770-779, 2017. https://doi.org/10.1016/j.egypro.2017.03.239

[6] A. H. Primicanta, M. Y. Nayan, and M. Awan, "ZigBee-GSM based automatic meter reading system," in 2010 International Conference on Intelligent and Advanced Systems, 2010, pp. 1-5: IEEE. https://doi.org/10.1109/icias.2010.5716223

[7] N. Javaid, A. Sharif, A. Mahmood, S. Ahmed, U. Qasim, and Z. A. Khan, "Monitoring and controlling power using zigbee communications," in 2012 Seventh International Conference on Broadband, Wireless Computing, Communication and Applications, 2012, pp. 608-613: IEEE. https://doi.org/10.1109/bwcca.2012.107

[8] V. S. Undre, R. N. Dhole, C. R. Solanki, S. R. Pawale, and R. C. Thool, "Advance energy management using GSM technology," in 2014 Students Conference on Engineering and Systems, 2014, pp. 1-4: IEEE. https://doi.org/10.1109/sces.2014.6880099

\section{$5 \quad$ Authors}

Haider Th. Salim ALRikabi is a Master of Electrical Engineering from California State University / Fullerton (CSUF)/USA. Works as Lecturer at Department of Electrical Engineering in University of Wasit of Al Kut city - Hay ALRabee, Wasit, Iraq. 
Contact: - +9647732212637. E-mail:- hdhiyab@uowasit.edu.iq. The number of articles in national databases -8 . The number of articles in international databases -8 .

Khalid Waleed Nasser is a Master of Electrical Engineering from The Great Saint Petersburg polytechnic university/Russia. Works as Lecturer at Department of Electrical Engineering in University of Misan. Contact:- +9647702787670. E-mail:- khalid.waleed@uomisan.edu.iq. The number of articles in national databases - 1. The number of articles in international databases -1 .

Abdul Hadi M. Alaidi is a Master of computer science from University of Bridgeport/USA works as a Lecturer at Department of Electrical Engineering in University of Wasit, Al Kut city - Hay ALRabee, Wasit, Iraq. E-mail:- alaidi@uowasit.edu.iq. The number of articles in national databases - .4The number of articles in international databases -2 .

Article submitted 2019-07-18. Resubmitted 2019-08-22. Final acceptance 2019-08-23. Final version published as submitted by the authors. 